\title{
Risk factors for Lyme disease stage and manifestation using electronic health records
}

\author{
Katherine A. Moon ${ }^{1 *} \mathbb{C}$, Jonathan S. Pollak', Melissa N. Poulsen², Christopher D. Heaney ${ }^{1,2,3}$, \\ Annemarie G. Hirsch ${ }^{1,2}$ and Brian S. Schwartz ${ }^{1,2,3,4}$
}

\begin{abstract}
Background: Little is known about risk factors for early (e.g., erythema migrans) and disseminated Lyme disease manifestations, such as arthritis, neurological complications, and carditis. No study has used both diagnoses and free text to classify Lyme disease by disease stage and manifestation.

Methods: We identified Lyme disease cases in 2012-2016 in the electronic health record (EHR) of a large, integrated health system in Pennsylvania. We developed a rule-based text-matching algorithm using regular expressions to extract clinical data from free text. Lyme disease cases were then classified by stage and manifestation using data from both diagnoses and free text. Among cases classified by stage, we evaluated individual, community, and health care variables as predictors of disseminated stage (vs. early) disease using Poisson regression models with robust errors. Final models adjusted for sociodemographic factors, receipt of Medical Assistance (i.e., Medicaid, a proxy for low socioeconomic status), primary care contact, setting of diagnosis, season of diagnosis, and urban/rural status.

Results: Among 7310 cases of Lyme disease, we classified 62\% by stage. Overall, 23\% were classified using both diagnoses and text, $26 \%$ were classified using diagnoses only, and $13 \%$ were classified using text only. Among the staged diagnoses $(n=4530), 30 \%$ were disseminated stage (762 arthritis, 426 neurological manifestations, 76 carditis, 95 secondary erythema migrans, and 76 other manifestations). In adjusted models, we found that persons on Medical Assistance at least $50 \%$ of time under observation, compared to never users, had a higher risk (risk ratio [95\% confidence interval]) of disseminated Lyme disease $(1.20[1.05,1.37])$. Primary care contact $(0.59[0.54,0.64])$ and diagnosis in the urgent care $(0.22[0.17,0.29])$, compared to the outpatient setting, were associated with lower risk of disseminated Lyme disease.

Conclusions: The associations between insurance payor, primary care status, and diagnostic setting with disseminated Lyme disease suggest that lower socioeconomic status and less health care access could be linked with disseminated stage Lyme disease. Intervening on these factors could reduce the individual and health care burden of disseminated Lyme disease. Our findings demonstrate the value of both diagnostic and narrative text data to identify Lyme disease manifestations in the EHR.
\end{abstract}

\footnotetext{
*Correspondence: kmoon9@jhu.edu

${ }^{1}$ Department of Environmental Health and Engineering, Johns Hopkins

Bloomberg School of Public Health, 615 N Wolfe St., W7604, Baltimore,

MD, USA

Full list of author information is available at the end of the article
} original author(s) and the source, provide a link to the Creative Commons licence, and indicate if changes were made. The images or other third party material in this article are included in the article's Creative Commons licence, unless indicated otherwise in a credit line to the material. If material is not included in the article's Creative Commons licence and your intended use is not permitted by statutory regulation or exceeds the permitted use, you will need to obtain permission directly from the copyright holder. To view a copy of this licence, visit http://creativecommons.org/licenses/by/4.0/. The Creative Commons Public Domain Dedication waiver (http://creativeco mmons.org/publicdomain/zero/1.0/) applies to the data made available in this article, unless otherwise stated in a credit line to the data. 
Keywords: Lyme disease, Tick-borne disease, Electronic health records, Epidemiology, Disease stage, Disseminated Lyme disease

\section{Introduction}

Lyme disease, caused by the bacteria Borrelia burgdorferi, is transmitted to humans through an infected tick bite. Most Lyme disease cases occur in the northeastern and midwestern United States (US); however, the geographic distribution of tick vectors and incidence of tickborne diseases has been expanding [1]. Recent estimates suggest that Lyme disease was treated and diagnosed in approximately 476,000 persons annually between 2010 and 2018 [2]. Lyme disease is commonly categorized into two main stages: early stage, where infection is localized (e.g., an expanding erythema migrans lesion), or disseminated stage, where infection has spread beyond the initial bite location [3-5]. Untreated, Lyme disease typically progresses from a localized skin infection, often with systemic non-specific symptoms (e.g., fatigue, headache), to various disseminated infections. Most uncomplicated cases fully recover after antibiotic treatment [6]. Disseminated manifestations range from secondary erythema migrans rashes, acute neurological effects (e.g., facial palsy, meningitis, radiculopathy), and carditis, which usually occur weeks to months after infection, to Lyme arthritis, the most common late disseminated infection, which usually occurs months to years after infection [3]. Only $30-50 \%$ of cases recall being bitten by a tick [7], and serological tests have low sensitivity early in the disease course [6]; therefore, early diagnosis largely relies on recognition of a characteristic erythema migrans rash. However, up to $20-30 \%$ of cases may not have erythema migrans [7], and atypical presentations of erythema migrans are more likely to be misdiagnosed $[8,9]$.

It is not well understood why some patients do not develop erythema migrans, or why others develop specific disseminated manifestations. Few epidemiologic studies have examined risk factors for disseminated stage Lyme disease, compared to early disease, or risk factors for developing specific manifestations. These studies have largely evaluated relations with demographic variables (age, sex, race, ethnicity), season of diagnosis, or with specific presenting clinical signs and symptoms [10-14]. Most studies identified Lyme disease cases and manifestations from surveillance data $[11,13,15,16]$ or from hospital or clinic data $[14,17,18]$. A recent study used billing codes in insurance claims from high-incidence states to identify disseminated Lyme disease manifestations, including arthritis, facial palsy, carditis, complete heart block, and meningitis, and evaluated trends in age, sex, seasonality, and hospitalization [10].
Like claims data, electronic health record (EHR) data contain rich longitudinal clinical data on diagnoses, medications, and laboratory test orders; however, EHR data also contain the results of laboratory testing and narrative free text notes added by a health care provider. Most EHR studies identify clinical outcomes using structured diagnosis data, such as diagnosis or billing codes; however, natural language processing algorithms are increasingly being developed to extract valuable clinical data from narrative text notes [19]. EHR and claims-based studies of Lyme disease have largely used diagnosis data to identify Lyme disease [2, 20-24]. Although prior EHR studies have identified erythema migrans using keywordbased text matching algorithms $[25,26]$, no studies have used both diagnosis data and narrative free text data to comprehensively classify Lyme disease diagnoses by stage of disease and manifestation. Classifying Lyme disease in the EHR will allow for future research to evaluate the effectiveness of intervening on modifiable risk factors for disseminated stage diagnosis that can reduce the burden of Lyme disease.

This study had two aims. First, we evaluated the classification ability of diagnosis data and free text from encounter notes to classify Lyme disease by stage of disease and clinical manifestation. Second, we examined whether individual, community-level, and health care factors were associated with disseminated stage compared to early stage Lyme disease.

\section{Methods}

\section{Study population}

Geisinger is an integrated health system that provides primary, specialty, urgent, and emergency health care services at community practice clinics and hospitals in central and northeastern Pennsylvania. For this study, we started with 1,128,671 patients in the Geisinger EHR (primary care and non-primary care) between January 2012 through December 2016 and whose most recent address was within Geisinger's primary service area and surrounding counties (38 counties).

\section{Lyme disease case identification}

We identified persons diagnosed with Lyme disease by the presence of at least one diagnosis for Lyme disease, using both Epic (Verona, WI) electronic diagnosis group (EDG) names or International Classification of Diseases Ninth and Tenth Revision, Clinical Modification (ICD9-CM 088.81 and ICD-10-CM A69.2x) codes (Additional 
file 1: Table S1). Relevant EDG names were identified using an iterative keyword search reviewed by a clinician (BSS). To focus on new diagnoses, we excluded persons with diagnoses indicating a history of Lyme disease up until six months prior to the index diagnosis. The Geisinger Institutional Review Board approved this study and waived informed consent. Hereafter, we will use the term "case" to describe persons who were diagnosed with Lyme disease.

\section{Classification of Lyme disease diagnoses by clinical stage and manifestation}

We categorized Lyme disease cases by clinical stage and manifestation using two sources, diagnoses associated with either encounters or medication orders, and narrative free text associated with an in-person outpatient, emergency, or urgent care encounter (Fig. 1). We classified Lyme disease cases as early localized (erythema migrans) or disseminated stage disease. Among those with disseminated stage disease, we further classified cases into four non-mutually exclusive groups: arthritis, neurological manifestations, carditis, and "other disseminated" manifestations. Manifestations were assigned when recorded within a day or less from a generic Lyme disease code.

We examined diagnoses (EDG names, ICD-10, ICD-9) for Lyme disease (Additional file 1: Table S1) and related co-diagnoses (Additional file 1: Table S2) from inpatient, outpatient, emergency, or urgent care encounters and from medication orders, and narrative free text from outpatient, emergency, or urgent care encounters within 31 days before or after the index Lyme disease diagnosis. EDG names allow for a higher level of diagnostic detail. EDG names can identify all Lyme disease manifestations, including erythema migrans, which cannot be identified using ICD codes. Based on the information related to stage and manifestation, diagnoses could be categorized as either: (1) a recognized manifestation of Lyme disease (e.g., Lyme arthritis), (2) information on stage but not manifestation (e.g., "early localized Lyme infection"); or (3) no information on disease stage or manifestation (e.g., "Lyme disease"). In cases with only generic Lyme disease

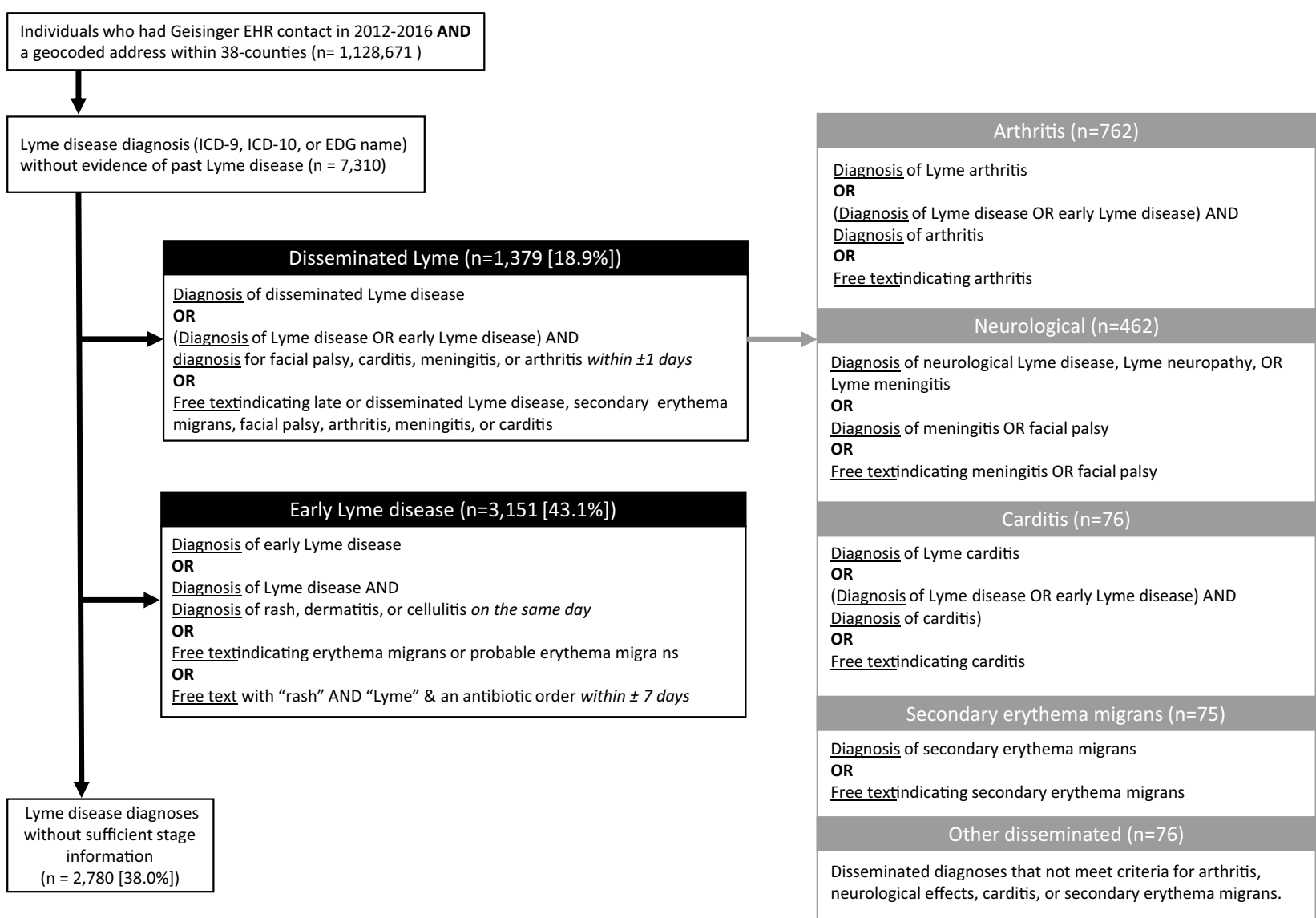

Fig. 1 Algorithm to classify Lyme disease cases by clinical stage and manifestation. ICD International Classification of Disease, EDG electronic diagnosis group 
diagnoses, we identified diagnoses related to manifestations of Lyme disease (e.g., rash, arthritis, meningitis) in order to determine stage or manifestation.

To extract diagnosis information from free text, we used regular expressions in Stata (MP, Version 15.1) to match words and phrases indicating Lyme disease stage or manifestation. Key words and phrases were developed using an iterative process led by a clinician (BSS), including a review of a subset of notes from a variety of years and settings to account for common misspellings and abbreviations. We identified strings of text before and after matched keywords to exclude where the concept was negated (e.g., "no sign of"), temporally unrelated, (e.g., "history of"), or unrelated to the subject (e.g., "husband has arthritis"). In cases with evidence for both early and disseminated stage Lyme disease, cases were classified as disseminated stage under the assumption that the presenting signs and symptoms were the later disseminated manifestations.

\section{Validation of EHR algorithm for early and disseminated stage Lyme disease}

We conducted a validation study to calculate the positive predictive value (PPV) of our EHR algorithm to classify Lyme disease cases as either early stage or disseminated stage. The PPV was calculated as the percentage of persons where the algorithm-assigned stage of Lyme disease was the same as the manual review-assigned stage of Lyme disease (reference standard). Two investigators (B.S and K.M) manually reviewed the EHR records. EHR documentation reviewed included demographics, health insurance payor, diagnoses (e.g., ICD codes and EDG names), Lyme disease serologic testing results, antibiotic medication orders, problem list, and free text clinical notes. Among Lyme disease cases that the EHR algorithm classified by stage of Lyme disease, we randomly selected a subset of 100 persons, 50 persons assigned as early stage and 50 persons assigned as disseminated stage. We stratified selection by year of diagnosis (10 persons per each of the 5 study years) because patterns of documentation, including for Lyme disease, have changed in the Geisinger EHR over time. We calculated 95\% confidence intervals for the PPV using a binomial test.

\section{Other variables}

We extracted individual-level covariates from the EHR, including age, sex, race, ethnicity, setting of diagnosis, and season of diagnosis. Exposure to disease-carrying ticks is most likely in the late spring and summer [7, 2729 ], and we hypothesized that compared to early stage cases, disseminated stage diagnosis would be more likely during other seasons. Individuals were defined as having primary care contact if they had two or more outpatient primary care encounters (e.g., family practice, internal medicine, pediatrics, and obstetrics/gynecology departments) prior to Lyme disease diagnosis. In Pennsylvania, Medical Assistance (i.e., Medicaid and Children's Health Insurance Program [CHIP]), pays for health care services for eligible individuals [30]. We considered the percentage of time an individual used Medical Assistance prior to Lyme disease diagnosis as a surrogate for household socioeconomic status (SES) [31].

In early stage Lyme disease, serology is not recommended due to a high probability of false negatives [32]. Blood samples drawn more than four weeks after disease onset are recommended to be tested for IgG, not IgM, because of high risk of false positive results with IgM at this stage [33, 34]. Consistent with prior analyses of the Geisinger EHR [21], we defined a positive Lyme disease serological test as either an IgG positive test (either alone, with a positive enzyme immunoassay [EIA], or with negative EIA), or an IgM positive test with a positive EIA within 30 days of diagnosis. The vast majority of Lyme disease diagnoses with positive IgG Western blots had a positive EIA (96.4\%), meeting the recommendations of the CDC diagnostic criteria ((CDC), 1995). For the cases with positive IgG Western blots without EIA (3.5\%) or with a negative EIA $(0.1 \%)$, we thought it was possible that the initial positive EIA was obtained and recorded outside of Geisinger and thus categorized these test results as seropositive. We defined evidence of appropriate treatment as a medication order for an appropriate antibiotic $[5,24]$ within 30 days before or after the Lyme disease diagnosis date.

We used geocoded addresses to assign community variables. Most addresses (88\%) were geocoded to the street address; otherwise, we assigned the zip code centroid. We used the U.S. Census Bureau categorization of urbanized area (50,000 or more people), urban clusters (at least 2500 and less than 50,000 people), or rural areas (persons not in urbanized areas or urban clusters) [35]. We hypothesized that disseminated Lyme disease may be more likely in rural areas, due to higher systemic and individual barriers to health care in rural areas compared to urban areas [36].

\section{Statistical analysis}

We first used descriptive analyses to evaluate selected individual, community, and health care variables among Lyme disease cases classified by stage and by manifestation. We evaluated how these variables differed across classified and unclassified cases, and by data source (e.g., both diagnoses and free text, diagnoses only, or free text only). To identify risk factors for disseminated disease, we conducted a case-only analysis of disseminated stage compared to early stage Lyme disease cases. With 
multivariable Poisson regression models using generalized estimating equations (GEE) with robust standard errors, we estimated risk ratios (RR) [37] of factors associated with disseminated stage Lyme disease (vs. early stage) and with specific disseminated manifestations (arthritis, neurological manifestations, carditis, secondary erythema migrans, or unspecified "other disseminated" manifestations vs. early stage). All models specified robust standard errors clustered within community (township, borough, or city census tract). Initial models were adjusted for a priori potential confounding variables. Final models included age $(<10,10$ to $<20,20$ to $<30,30$ to $<50,50$ to $<70$ [reference], and $70+$ years), sex (female, male [reference]), race (non-white, white [reference]), use of Medical Assistance ( $0 \%$ [reference], $>0$ to $<50 \%$, and $50-100 \%$ of prior observation time), primary care contact (yes, no [reference]), setting of diagnosis (outpatient [reference], urgent care, emergency, inpatient), season of diagnosis (winter, spring, summer [reference], fall), and urban/rural status (urban, urban cluster, or rural area [reference]). In exploratory analyses, we evaluated whether sex, Medical Assistance, or season modified relations between setting of diagnosis and Lyme disease stage by including relevant cross-product terms in separate models, fully adjusted for all covariates. We conducted statistical analyses in Stata (MP, Version 14).

To address potential outcome misclassification, we evaluated a model in which disseminated cases were required to have positive serology (IgG or IgM). We hypothesized that requiring a positive serology result would exclude false positive cases (e.g., due to coding errors or "rule-out" laboratory tests) but would also exclude some true cases (e.g., in which serology was conducted outside Geisinger or tested before antibodies were detectable).

\section{Results}

Lyme disease cases classified by stage and manifestation

We identified 7310 cases of Lyme disease between 2012 and 2016 that met inclusion criteria (Fig. 1). Using diagnoses and narrative free text, we classified 4530 cases (62\%) as early or disseminated stage. Of the classified cases, $70 \%$ were classified as early stage disease. Of the 1,359 disseminated cases, Lyme arthritis was the most common manifestation (55\%), followed by neurological manifestations (34\%), carditis (6\%), and secondary erythema migrans (7\%). Diagnoses classified as disseminated stage that did not meet criteria for arthritis, neurological effects, carditis, or secondary erythema migrans were classified as "other disseminated" manifestations (6\%). In a validation sample of 50 early and 50 disseminated cases, we found that the PPV of early stage disease was 92\% (95\% CI 81-98\%) and the PPV of disseminated stage
Lyme disease was 88\% (95\% CI 76-95\%). Lyme disease cases were distributed across the study area in central and northeastern Pennsylvania (Fig. 2).

\section{Classified Lyme disease cases by source of staging information}

Among all persons diagnosed with Lyme disease $(\mathrm{n}=7310), 23 \%$ were classified using information in both diagnoses and text, $26 \%$ were classified using information in diagnoses only, $13 \%$ were classified using information in text only, and $38 \%$ were not classified. Overall, diagnoses were able to classify $49 \%$, compared to $36 \%$ with free text. The percentage of diagnoses classified increased over the study period: persons classified by stage using diagnoses increased from 43 to $50 \%$ and cases classified by text increased from 21 to $55 \%$.

Among Lyme disease cases classified by stage $(n=4530)$, we observed notable patterns of sources of staging data over time and by participant characteristics (Additional file 1: Table S3). Over the study period, the percentage of classified cases with information in diagnoses alone decreased from 60 to 21\%, while cases classified by text alone increased from 19 to $27 \%$. Cases with staging-relevant data from both diagnoses and text were younger, while cases with staging data only in text were older. The most common source of data for staging varied by setting of diagnosis, primary care contact, and time using Medical Assistance.

\section{Cases classified by stage compared to cases not classified by stage}

Lyme disease cases who were classified by stage $(62 \%$, $\mathrm{n}=4530$ ) differed from those who were not (38\%) (Additional file 1: Table S4). Over the study period, the percentage of cases classified increased from 54 to $69 \%$. Classified cases were younger, more likely to be diagnosed in the summer, and more likely to live in a rural area. Cases with sufficient information relevant to staging were more likely to be diagnosed in urgent care, less likely to be diagnosed in the emergency department, and more likely to have primary care contact.

\section{Characteristics of early and disseminated stage Lyme disease cases}

We observed several differences in individual, community, and healthcare characteristics across Lyme disease stages and manifestations (Table 1). The secondary erythema migrans group and the "other disseminated" manifestations group had the lowest median age, followed by arthritis, and neurological manifestations and carditis. Lyme carditis was less commonly observed in females, whereas other manifestations were more equally distributed among men and women. Lyme disease cases were 


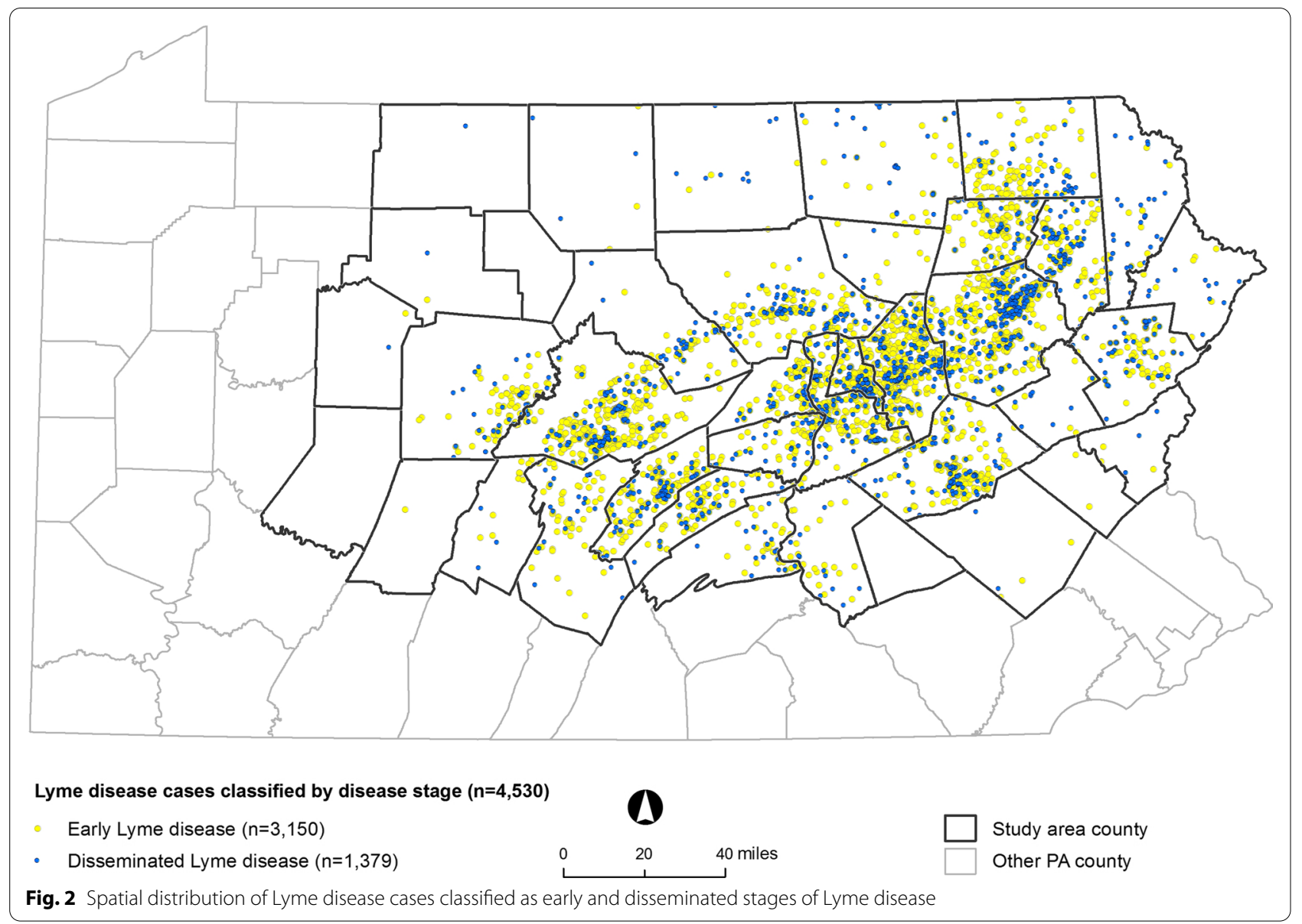

most commonly diagnosed in outpatient settings; however, Lyme carditis was more evenly split between inpatient and outpatient settings. Diagnosis in summer was most common across manifestations, except for Lyme arthritis, which was diagnosed relatively equally in fall and summer. For most early (94.5\%) and disseminated (82.3\%) cases, an appropriate antibiotic was ordered within 30 days. Among disseminated stage cases, when serology is most likely recommended, most cases (59\%) had at least one serologic test order within 30 days. Just under half of all disseminated cases had positive IgG or IgM serology (45\% overall, $77 \%$ of cases with test orders).

\section{Disseminated vs. early stage Lyme disease}

In a multivariable model examining risk factors of disseminated versus early stage Lyme disease, we observed several interesting associations (risk ratio [95\% confidence interval]) (Table 2). Compared to persons with $0 \%$ of time using Medical Assistance, persons who used Medical Assistance for $50 \%$ or more time prior to Lyme disease diagnosis had a higher risk of disseminated Lyme disease overall $(1.20[1.05,1.37])$, arthritis (1.37 [1.15,
$1.64])$, and neurological manifestations $(1.22[0.93,1.60])$, no difference in risk of carditis $(1.04[0.47,2.27])$, but a lower risk of secondary erythema migrans (0.50 [0.24, $1.22])$ and other disseminated stage $(0.15$ [0.02, 1.16]). Individuals with primary care contact had lower risk of other disseminated disease $(0.59$ [0.54, 0.64]). Compared to outpatient settings, we found that the inpatient diagnosis was associated with higher risk of disseminated stage $(2.21[1.98,2.47])$ while urgent care was associated with lower risk of disseminated stage $(0.22$ [0.17, 0.29]). Emergency department diagnosis was associated with higher odds of neurological Lyme disease (1.47 [1.07, 2.02]). Higher risk of disseminated Lyme disease, particularly Lyme arthritis, were observed in cases diagnosed in winter $(4.54[3.84,5.37])$, followed by fall $(2.75$ $[2.35,3.22])$ and spring $(2.53[2.10,3.04])$, compared to summer.

In sensitivity analyses to address possible misclassification of our Lyme disease definition, inferences were similar to the main analysis when we required disseminated cases to have positive serology (IgG or IgM, $45 \%$ of disseminated cases) (Additional file 1: Table S5), or an 
Table 1 Selected characteristics of 3151 early stage and 1379 disseminated stage Lyme disease cases in the Geisinger electronic health record, 2012-2016

\begin{tabular}{|c|c|c|c|c|c|c|c|}
\hline \multirow[t]{3}{*}{ Characteristic } & \multirow{3}{*}{$\begin{array}{l}\text { Early Lyme disease } \\
\mathrm{n}=3151\end{array}$} & \multirow{3}{*}{$\begin{array}{l}\text { Disseminated } \\
\text { Lyme disease } \\
\mathrm{n}=1379 \\
\end{array}$} & \multicolumn{5}{|c|}{ Disseminated manifestations } \\
\hline & & & \multirow{2}{*}{$\begin{array}{l}\text { Arthritis } \\
n=762\end{array}$} & \multirow{2}{*}{$\begin{array}{l}\text { Neurological } \\
\text { manifestations } \\
n=426\end{array}$} & \multirow{2}{*}{$\begin{array}{l}\text { Carditis } \\
\mathbf{n}=76\end{array}$} & \multirow{2}{*}{$\begin{array}{l}\text { Secondary } \\
\text { erythema } \\
\text { migrans } \\
\mathrm{n}=95\end{array}$} & \multirow{2}{*}{$\begin{array}{l}\text { Other } \\
\text { disseminated } \\
\text { manifestations } \\
\mathrm{n}=76\end{array}$} \\
\hline & & & & & & & \\
\hline Sex, female, n (\%) & $1426(45.3 \%)$ & $618(44.8 \%)$ & $346(45.4 \%)$ & $194(45.5 \%)$ & $21(27.6 \%)$ & 47 (49.5\%) & $40(52.6 \%)$ \\
\hline $\begin{array}{l}\text { Age, years, median } \\
\text { (IQR) }\end{array}$ & $40.7(12.9,59.8)$ & $31.5(10.8,57.3)$ & $28.6(9.8,57.2)$ & $37.8(14.9,57.2)$ & $39.1(20.7,58.9)$ & $17.9(7.5,57.4)$ & $17.5(8.7,53.4)$ \\
\hline \multicolumn{8}{|l|}{ Age, $\mathrm{n}(\%)$} \\
\hline$<10$ years & $627(19.9 \%)$ & $311(22.6 \%)$ & $196(25.7 \%)$ & $66(15.5 \%)$ & $3(4.0 \%)$ & $32(33.7 \%)$ & $25(32.9 \%)$ \\
\hline 10 to $<20$ years & $384(12.2 \%)$ & $261(18.9 \%)$ & $141(18.5 \%)$ & $77(18.1 \%)$ & 15 (19.7\%) & $18(18.9 \%)$ & $16(21.1 \%)$ \\
\hline 20 to $<30$ years & $244(7.7 \%)$ & $100(7.3 \%)$ & $51(6.7 \%)$ & $35(8.2 \%)$ & $13(17.1 \%)$ & $7(7.4 \%)$ & $1(1.3 \%)$ \\
\hline 30 to $<50$ years & $642(20.4 \%)$ & $249(18.1 \%)$ & $118(15.5 \%)$ & $101(23.7 \%)$ & $18(23.7 \%)$ & $8(8.4 \%)$ & $13(17.1 \%)$ \\
\hline 50 to $<70$ years & $952(30.2 \%)$ & $333(24.2 \%)$ & $188(24.7 \%)$ & $110(25.8 \%)$ & $19(25.0 \%)$ & $20(21.1 \%)$ & $15(19.7 \%)$ \\
\hline$>70$ years & $302(9.6 \%)$ & $125(9.1 \%)$ & $68(8.9 \%)$ & $37(8.7 \%)$ & $8(10.5 \%)$ & $10(10.5 \%)$ & $6(7.9 \%)$ \\
\hline $\begin{array}{l}\text { Race/ethnicity, non- } \\
\text { White, } n(\%)^{\mathrm{a}}\end{array}$ & $34(1.1 \%)$ & $25(1.8 \%)$ & $14(1.8 \%)$ & $8(1.9 \%)$ & $0(0 \%)$ & $1(1.1 \%)$ & $3(3.9 \%)$ \\
\hline \multicolumn{8}{|l|}{ Year of diagnosis, n (\%) } \\
\hline 2012 & $322(10.2 \%)$ & $234(17.0 \%)$ & $163(21.4 \%)$ & $51(12.0 \%)$ & $6(7.9 \%)$ & $12(12.6 \%)$ & $9(11.8 \%)$ \\
\hline 2013 & $527(16.7 \%)$ & $235(17.0 \%)$ & $134(17.6 \%)$ & $78(18.3 \%)$ & $17(22.4 \%)$ & $8(8.4 \%)$ & $9(11.8 \%)$ \\
\hline 2014 & $607(19.3 \%)$ & $278(20.2 \%)$ & $149(19.6 \%)$ & 89 (20.1\%) & $19(25 \%)$ & $24(25.3 \%)$ & $10(13.2 \%)$ \\
\hline 2015 & $765(24.3 \%)$ & $278(20.2 \%)$ & $145(19.0 \%)$ & $96(22.5 \%)$ & $11(14.5 \%)$ & $20(21.1 \%)$ & $15(19.7 \%)$ \\
\hline 2016 & $90(29.5 \%)$ & $354(25.7 \%)$ & $171(22.4 \%)$ & $112(26.3 \%)$ & $23(30.3 \%)$ & $31(32.6 \%)$ & $33(43.4 \%)$ \\
\hline \multicolumn{8}{|c|}{ Season of diagnosis, n (\%) } \\
\hline Winter (Dec-Feb) & $109(3.5 \%)$ & $181(13.1 \%)$ & $145(19.0 \%)$ & $30(7.0 \%)$ & $2(2.6 \%)$ & $4(4.2 \%)$ & $5(6.6 \%)$ \\
\hline $\begin{array}{l}\text { Spring (March- } \\
\text { May) }\end{array}$ & $356(11.3 \%)$ & $181(13.1 \%)$ & $140(18.4 \%)$ & $36(8.5 \%)$ & $4(5.2 \%)$ & $8(8.4 \%)$ & $3(3.9 \%)$ \\
\hline $\begin{array}{l}\text { Summer (June- } \\
\text { Aug) }\end{array}$ & $2110(67.0 \%)$ & $653(47.4 \%)$ & $222(29.1 \%)$ & $289(67.8 \%)$ & $54(71.1 \%)$ & $69(72.6 \%)$ & $52(68.4 \%)$ \\
\hline Fall (Sept-Nov) & $576(18.3 \%)$ & $364(26.4 \%)$ & $255(33.5 \%)$ & $71(16.7 \%)$ & $16(21.1 \%)$ & $14(14.7 \%)$ & $16(21.1 \%)$ \\
\hline \multicolumn{8}{|c|}{ Setting of diagnosis, n (\%) } \\
\hline Outpatient & $2312(73.4 \%)$ & $1110(80.5 \%)$ & $667(87.5 \%)$ & $310(72.8 \%)$ & $33(43.4 \%)$ & $80(84.2 \%)$ & $66(86.8 \%)$ \\
\hline Urgent care & $667(21.5 \%)$ & $56(4.1 \%)$ & $32(4.2 \%)$ & $13(3.1 \%)$ & $0(0 \%)$ & $11(11.6 \%)$ & $1(1.3 \%)$ \\
\hline Emergency & $131(4.2 \%)$ & $77(5.6 \%)$ & $28(3.7 \%)$ & $39(9.2 \%)$ & $4(5.3 \%)$ & $4(4.2 \%)$ & $3(3.9 \%)$ \\
\hline Inpatient & $31(1.0 \%)$ & $136(9.9 \%)$ & $35(4.6 \%)$ & $64(15.0 \%)$ & $39(51.3 \%)$ & $0(0.0 \%)$ & $6(7.9 \%)$ \\
\hline $\begin{array}{l}\text { Primary care con- } \\
\text { tact, yes, } \mathrm{n}(\%)\end{array}$ & $2619(83.1 \%)$ & $948(68.8 \%)$ & $540(70.9 \%)$ & $287(67.4 \%)$ & $43(56.6 \%)$ & $80(84.2 \%)$ & $38(50.0 \%)$ \\
\hline \multicolumn{8}{|c|}{ Medical assistance, n (\%) } \\
\hline 0\% time & $2554(81.1 \%)$ & 1061 (76.9\%) & $571(74.9 \%)$ & $336(78.9 \%)$ & 60 (78.9\%) & $76(80.0 \%)$ & $59(77.6 \%)$ \\
\hline $\begin{array}{l}>0 \% \text { to }<50 \% \\
\text { time }\end{array}$ & $370(11.7 \%)$ & $156(11.3 \%)$ & $83(10.9 \%)$ & $45(10.6 \%)$ & $8(10.5 \%)$ & $13(13.7 \%)$ & $16(21.1 \%)$ \\
\hline$\geq 50 \%$ time & $227(7.2 \%)$ & $162(11.7 \%)$ & $108(14.2 \%)$ & $45(10.6 \%)$ & $8(10.5 \%)$ & $6(6.3 \%)$ & $1(1.3 \%)$ \\
\hline \multicolumn{8}{|c|}{ Community of residence, $\mathrm{n}(\%)$} \\
\hline Township & $2424(76.9 \%)$ & $1002(72.7 \%)$ & $564(74.0 \%)$ & $299(70.2 \%)$ & $50(65.8 \%)$ & $72(75.8 \%)$ & $55(72.4 \%)$ \\
\hline Borough & $613(19.5 \%)$ & $309(22.4 \%)$ & $163(21.4 \%)$ & $97(22.8 \%)$ & $24(31.6 \%)$ & $22(23.2 \%)$ & $19(25.0 \%)$ \\
\hline City & $114(3.6 \%)$ & $68(4.9 \%)$ & $35(4.6 \%)$ & $30(7.0 \%)$ & $2(2.6 \%)$ & $1(1.1 \%)$ & $2(2.6 \%)$ \\
\hline \multicolumn{8}{|c|}{ Urban/rural residence, n (\%) } \\
\hline Rural & $1987(63.1 \%)$ & $820(59.5 \%)$ & $459(60.2 \%)$ & $251(58.9 \%)$ & 44 (57.9\%) & $57(60.0 \%)$ & $45(59.2 \%)$ \\
\hline Urban cluster & $465(14.8 \%)$ & $239(17.3 \%)$ & $134(17.6 \%)$ & $76(17.8 \%)$ & $12(15.8 \%)$ & $19(20.0 \%)$ & $19(25.0 \%)$ \\
\hline Urbanized area & $699(22.2 \%)$ & $320(23.2 \%)$ & $169(22.2 \%)$ & $99(23.2 \%)$ & $20(26.3 \%)$ & $19(20.0 \%)$ & $12(15.8 \%)$ \\
\hline
\end{tabular}


Table 1 (continued)

\begin{tabular}{|c|c|c|c|c|c|c|c|}
\hline \multirow[t]{3}{*}{ Characteristic } & \multirow[t]{2}{*}{ Early Lyme disease } & \multirow{2}{*}{$\begin{array}{l}\text { Disseminated } \\
\text { Lyme disease }\end{array}$} & \multicolumn{5}{|c|}{ Disseminated manifestations } \\
\hline & & & \multirow{2}{*}{$\begin{array}{l}\text { Arthritis } \\
n=762\end{array}$} & \multirow{2}{*}{$\begin{array}{l}\begin{array}{l}\text { Neurological } \\
\text { manifestations }\end{array} \\
n=426\end{array}$} & \multirow{2}{*}{$\begin{array}{l}\text { Carditis } \\
\mathrm{n}=76\end{array}$} & \multirow{2}{*}{$\begin{array}{l}\text { Secondary } \\
\text { erythema } \\
\text { migrans } \\
\mathrm{n}=95\end{array}$} & \multirow{2}{*}{$\begin{array}{l}\begin{array}{l}\text { Other } \\
\text { disseminated } \\
\text { manifestations } \\
\mathrm{n}=76\end{array}\end{array}$} \\
\hline & $\mathrm{n}=3151$ & $n=1379$ & & & & & \\
\hline \multicolumn{8}{|c|}{ Community socioeconomic deprivation, n (\%) } \\
\hline Quartile 1 & $918(29.1 \%)$ & $355(25.7 \%)$ & $198(26.0 \%)$ & $103(24.2 \%)$ & $26(34.2 \%)$ & $25(26.3 \%)$ & $18(23.7 \%)$ \\
\hline Quartile 2 & $1031(32.7 \%)$ & $423(30.7 \%)$ & $234(30.7 \%)$ & $125(29.3 \%)$ & $20(26.3 \%)$ & $38(40.0 \%)$ & $26(34.2 \%)$ \\
\hline Quartile 3 & $746(23.7 \%)$ & $370(26.8 \%)$ & $201(26.4 \%)$ & $119(27.9 \%)$ & $17(22.4 \%)$ & $17(17.9 \%)$ & $23(30.3 \%)$ \\
\hline Quartile 4 & $456(14.5 \%)$ & $231(16.8 \%)$ & $129(16.9 \%)$ & $79(18.5 \%)$ & $13(17.1 \%)$ & $15(15.8 \%)$ & $9(11.8 \%)$ \\
\hline $\begin{array}{l}\text { Antibiotic order } \\
\text { within } \pm 30 \text { days, } \\
n(\%)^{c}\end{array}$ & $2977(94.5 \%)$ & $1135(82.3 \%)$ & $618(81.1 \%)$ & $349(81.9 \%)$ & $64(84.2 \%)$ & $88(92.6 \%)$ & $59(77.6 \%)$ \\
\hline $\begin{array}{l}\text { Lyme disease serol- } \\
\text { ogy order } \pm 30 \text { days, } \\
\text { n (\%) }\end{array}$ & $-{ }^{b}$ & $810(58.7 \%)$ & $468(61.4 \%)$ & $240(56.3 \%)$ & $36(47.4 \%)$ & 42 (44.2\%) & $34(44.7 \%)$ \\
\hline $\begin{array}{l}\lg G+W B \text { or EIA+/ } \\
\text { lgM+WB } \pm 30 \text { days, } \\
\text { n (\%) }\end{array}$ & $-{ }^{b}$ & $621(45.0 \%)$ & 333 (43.7\%) & $202(47.4 \%)$ & $49(64.5 \%)$ & $30(31.6 \%)$ & 29 (38.2\%) \\
\hline
\end{tabular}

$I Q R$ interquartile range, $I g G$ immunoglobulin $\mathrm{G}$, $I g M$ immunoglobulin $\mathrm{M}$, WB Western blot, EIA enzyme immunoassay

${ }^{a}$ Race was recorded as white, Black or African American, American Indian or Alaska Native, Asian, Native Hawaiian or Pacific Islander, mixed, or unknown. In this sample, non-White race/ethnicity included 42\% Black or African American, 31.8\% American Indian or Alaska Native, Asian, Native Hawaiian or Pacific Islander, 11.8\% mixed race, and $9.1 \%$ unknown race

${ }^{b}$ Serological diagnostic testing is not recommended for early stage Lyme disease cases because of a high probability of false negative results before a robust antibody-mediated immune response

'Lyme disease-appropriate antibiotic order, as previously described [20]

antibiotic order within 30 days before or after the diagnosis date (Additional file 1: Table S6). In exploratory models of effect modification, we found statistical interactions between time on Medical Assistance and setting of diagnosis $(\mathrm{p}=0.007)$ and season and setting of diagnosis $(\mathrm{p}<0.001)$; however, the associations were qualitatively similar to the overall model (results not shown).

\section{Discussion}

In this study, we used clinical data in diagnoses and narrative text from the Geisinger EHR to classify $62 \%$ of Lyme disease cases by disease stage and manifestation. Diagnoses, particularly the EDG names that could specifically identify all early and disseminated manifestations, were able to classify $48 \%$ of cases. With a novel rule-based text-matching algorithm, we extracted staging information from narrative free text, and classified an additional $13 \%$ of cases that could not be classified using diagnoses alone. We observed similar proportions of Lyme disease manifestations compared to the patterns observed in surveillance data and identified novel associations with SES- and health care-related variables. Medical Assistance, a proxy of low SES, was associated with higher odds of disseminated disease, while primary care contact and diagnosis in the urgent care setting (compared to outpatient) were associated with lower odds of disseminated disease. These findings inform future research to determine whether improvements in SES or healthcare access can improve timely diagnosis and treatment of Lyme disease and whether targeted interventions on these factors could prevent disseminated disease.

In this study, we used both diagnoses and narrative free text to identify stage and manifestations of Lyme disease. EDG names could identify all early and disseminated Lyme disease endpoints. With ICD-10, a provider could specify a disseminated Lyme manifestation (e.g., arthritis, meningitis, other neurologic endpoints [A69.2x]), whereas with ICD-9, a provider needed both a generic Lyme disease code (088.81) and a co-diagnosis (e.g., arthritis [711.8x]) to indicate a specific manifestation. Changes in available diagnoses could have influenced classification trends over time; however, EDG names and ICD-10 codes were available throughout the study period, while ICD-9 codes were used for the small proportion of encounters $(<10 \%)$ where they were available (inpatient and emergency encounters before 2015). Over the study period, the proportion of all Lyme disease cases staging-relevant information in free text increased from 21 to $55 \%$. By the end of the study, 18\% of diagnoses (27\% of classified by stage) had staging-relevant information in free text that was not available in diagnoses. We hypothesize that these temporal trends were largely the 
Table 2 Adjusted associations (risk ratio, 95\% confidence interval) of independent variables with Lyme disease stage (disseminated vs. early stage)

\begin{tabular}{|c|c|c|c|c|c|}
\hline \multirow{2}{*}{$\begin{array}{l}\text { All disseminated } \\
\text { vs. early Lyme } \\
\text { disease }\end{array}$} & \multicolumn{5}{|c|}{ Disseminated manifestation vs. early Lyme disease } \\
\hline & Arthritis & $\begin{array}{l}\text { Neurological } \\
\text { manifestations }\end{array}$ & Carditis & $\begin{array}{l}\text { Secondary } \\
\text { erythema migrans }\end{array}$ & Other disseminated \\
\hline $\begin{array}{l}1379 / 3151 \\
\text { (disseminated vs. } \\
\text { early) }\end{array}$ & $\begin{array}{l}762 / 3151 \\
\text { (arthritis vs. } \\
\text { early) }\end{array}$ & $\begin{array}{l}426 / 3151 \\
\text { (neurological vs. } \\
\text { early) }\end{array}$ & $\begin{array}{l}76 / 2446^{a} \text { (carditis } \\
\text { vs. early) }\end{array}$ & $\begin{array}{l}95 / 3120^{a} \\
\text { (secondary } \\
\text { erythema migrans } \\
\text { vs. early) }\end{array}$ & $\begin{array}{l}\text { 76/3151 (other } \\
\text { disseminated vs. } \\
\text { early) }\end{array}$ \\
\hline
\end{tabular}

\begin{tabular}{|c|c|c|c|c|c|c|}
\hline \multicolumn{7}{|l|}{ Age (years) } \\
\hline 0 to $<10$ & $1.24(1.08,1.42)$ & $1.25(1.05,1.48)$ & $1.04(0.77,1.39)$ & $0.39(0.13,1.21)$ & $2.59(1.47,4.57)$ & $2.66(1.33,5.35)$ \\
\hline 10 to $<20$ & $1.44(1.28,1.63)$ & $1.38(1.16,1.63)$ & $1.61(1.24,2.10)$ & $1.45(0.83,2.55)$ & $2.41(1.26,4.58)$ & $2.56(1.23,5.34)$ \\
\hline 20 to $<30$ & $1.21(1.00,1.46)$ & $1.16(0.89,1.51)$ & $1.41(0.99,2.02)$ & $2.01(0.94,4.31)$ & $1.54(0.63,3.75)$ & $0.31(0.04,2.19)$ \\
\hline 30 to $<50$ & $1.13(0.99,1.29)$ & $0.99(0.82,1.21)$ & $1.39(1.09,1.77)$ & $1.30(0.75,2.24)$ & $0.64(0.30,1.36)$ & $1.30(0.64,2.65)$ \\
\hline 50 to $<70$ & 1.00 (Reference) & 1.00 (Reference) & 1.00 (Reference) & 1.00 (Reference) & 1.00 (Reference) & 1.00 (Reference) \\
\hline $70+$ & $1.14(0.96,1.35)$ & $1.13(0.88,1.47)$ & $1.08(0.77,1.53)$ & $1.00(0.43,2.36)$ & $1.57(0.73,3.38)$ & $1.20(0.46,3.08)$ \\
\hline \multicolumn{7}{|l|}{ Sex } \\
\hline Male & 1.00 (Reference) & 1.00 (Reference) & 1.00 (Reference) & 1.00 (Reference) & 1.00 (Reference) & 1.00 (Reference) \\
\hline Female & $1.01(0.93,1.09)$ & $1.00(0.89,1.12)$ & $1.06(0.90,1.25)$ & $0.94(0.55,1.61)$ & $1.20(0.83,1.74)$ & $1.40(0.88,2.21)$ \\
\hline \multicolumn{7}{|l|}{ Race/ethnicity } \\
\hline White & 1.00 (Reference) & 1.00 (Reference) & 1.00 (Reference) & 1.00 (Reference) & 1.00 (Reference) & 1.00 (Reference) \\
\hline Non-White & $1.25(0.93,1.67)$ & $1.18(0.78,1.80)$ & $1.33(0.71,2.49)$ & NA & $0.93(0.13,6.57)$ & $2.07(0.72,5.98)$ \\
\hline \multicolumn{7}{|l|}{ Medical assistance } \\
\hline 0\% time & 1.00 (Reference) & 1.00 (Reference) & 1.00 (Reference) & 1.00 (Reference) & 1.00 (Reference) & 1.00 (Reference) \\
\hline $\begin{array}{l}>0 \% \text { to }<50 \% \\
\text { time }\end{array}$ & $0.97(0.85,1.11)$ & $0.94(0.78,1.14)$ & $0.87(0.65,1.16)$ & $1.03(0.56,1.89)$ & $0.85(0.48,1.49)$ & $1.66(0.97,2.84)$ \\
\hline$\geq 50 \%$ time & $1.20(1.05,1.37)$ & $1.37(1.15,1.64)$ & $1.22(0.93,1.60)$ & $1.04(0.47,2.27)$ & $0.54(0.24,1.22)$ & $0.15(0.02,1.16)$ \\
\hline \multicolumn{7}{|c|}{ Primary care contact } \\
\hline No & 1.00 (Reference) & 1.00 (Reference) & 1.00 (Reference) & 1.00 (Reference) & 1.00 (Reference) & 1.00 (Reference) \\
\hline Yes & $0.59(0.54,0.64)$ & $0.55(0.48,0.63)$ & $0.44(0.36,0.54)$ & $0.51(0.30,0.86)$ & $0.75(0.42,1.34)$ & $0.13(0.08,0.20)$ \\
\hline \multicolumn{7}{|l|}{ Setting of diagnosis } \\
\hline Outpatient & 1.00 (Reference) & 1.00 (Reference) & 1.00 (Reference) & 1.00 (Reference) & 1.00 (Reference) & 1.00 (Reference) \\
\hline Urgent care & $0.22(0.17,0.29)$ & $0.22(0.15,0.31)$ & $0.12(0.06,0.21)$ & NA & $0.47(0.23,0.93)$ & $0.027(0.003,0.21)$ \\
\hline Emergency & $1.04(0.85,1.27)$ & $0.73(0.50,1.06)$ & $1.49(1.09,2.04)$ & $1.30(0.48,3.54)$ & $0.87(0.31,2.45)$ & $0.51(0.16,1.60)$ \\
\hline Inpatient & $2.21(1.98,2.47)$ & $1.88(1.49,2.36)$ & $4.12(3.30,5.14)$ & $25.4(15.22,42.50)$ & NA & $3.84(1.59,9.25)$ \\
\hline \multicolumn{7}{|l|}{ Season of diagnosis } \\
\hline Winter (Dec-Feb) & $2.19(1.96,2.45)$ & $4.54(3.84,5.37)$ & $1.45(1.03,2.03)$ & $0.78(0.25,2.41)$ & $1.17(0.44,3.17)$ & $1.25(0.54,2.91)$ \\
\hline $\begin{array}{l}\text { Spring (March- } \\
\text { May) }\end{array}$ & $1.35(1.18,1.54)$ & $2.53(2.10,3.04)$ & $0.77(0.57,1.05)$ & $0.70(0.25,1.97)$ & $0.69(0.34,1.39)$ & $0.34(0.11,1.06)$ \\
\hline $\begin{array}{l}\text { Summer (June-- } \\
\text { Aug) }\end{array}$ & 1.00 (Reference) & 1.00 (Reference) & 1.00 (Reference) & 1.00 (Reference) & 1.00 (Reference) & 1.00 (Reference) \\
\hline Fall (Sept-Nov) & $1.46(1.33,1.62)$ & $2.75(2.35,3.22)$ & $0.84(0.67,1.07)$ & $1.31(0.80,2.16)$ & $0.75(0.42,1.33)$ & $0.92(0.54,1.56)$ \\
\hline \multicolumn{7}{|c|}{ Urban/rural residence } \\
\hline Rural & 1.00 (Reference) & 1.00 (Reference) & 1.00 (Reference) & 1.00 (Reference) & 1.00 (Reference) & 1.00 (Reference) \\
\hline Urban cluster & $1.10(0.99,1.22)$ & $1.13(0.97,1.32)$ & $1.20(0.95,1.52)$ & $1.29(0.70,2.39)$ & $1.33(0.83,2.14)$ & $1.18(0.66,2.13)$ \\
\hline Urbanized area & $1.09(0.98,1.21)$ & $1.09(0.94,1.26)$ & $1.11(0.90,1.38)$ & $1.42(0.95,2.12)$ & $0.95(0.54,1.68)$ & $1.32(0.77,2.26)$ \\
\hline
\end{tabular}

NA not available

${ }^{a}$ No persons with Lyme carditis were non-White and none were diagnosed in the urgent care setting; therefore, non-cases (i.e., early stage cases) who were Non-White or diagnosed in the urgent care setting were excluded from the carditis model. No persons with secondary erythema migrans were diagnosed in the inpatient setting; therefore, early stage cases who were diagnosed in the inpatient setting were excluded from the secondary erythema migrans model 
result of concurrent administrative and legal incentives to increase the volume and richness of clinical information in narrative free text. Historically, most EHR-based epidemiologic studies have identified clinical outcomes using ICD diagnosis codes alone, but extracting information from free text is increasingly common [19]. EHR studies of Lyme disease, however, have previously used narrative text only to identify erythema migrans $[25,26]$. Our results suggest that EHR free text can yield valuable information on Lyme disease stage and manifestations beyond what is available from diagnoses alone.

This study classified $70 \%$ of Lyme disease cases who could be staged as early stage and $30 \%$ as disseminated stage. Importantly, the approximately $90 \%$ PPV observed in the validation sample was consistent with a common acceptable level for validation of EHR algorithms [38]. This distribution is in line with national surveillance data, where $72 \%$ of confirmed Lyme disease cases had erythema migrans and $28 \%$ had at least one disseminated manifestation, with arthritis being the most common (28\%), followed by neurologic endpoints (13\%) and carditis (2\%) [11]. Information on manifestation was only available for $60 \%$ of confirmed surveillance cases [11], which is comparable to $62 \%$ of cases classified in our study. A recent claims data study from high-incidence US states categorized only $6 \%$ of cases as disseminated stage; however, this is likely an underestimate because they identified disseminated cases by a clinically relevant billing code (e.g., arthritis, facial palsy) within 30 days of a generic Lyme disease diagnosis and assumed cases that did not meet these criteria were early stage [10].

We observed similar patterns across age, sex, and season of diagnosis across Lyme disease manifestations as observed in prior studies. In national surveillance data, the frequency of Lyme arthritis is more common among children and adolescents [11] while carditis is more common in young adults, especially young men [16]. Our observations of similar proportions of manifestations to national surveillance for Lyme disease, which is known to over-represent more severe, disseminated cases [24, 39], could suggest common sources of bias less health care provider documentation of uncomplicated, less severe cases in the EHR.

In a Lyme disease vaccine clinical trial, only $2-3 \%$ of the 296 definite, possible, or asymptomatic Lyme disease cases developed disseminated manifestations [4]. In a study of 88,022 persons diagnosed with Lyme disease in claims data in high-incidence states, $2.8 \%$ cases had arthritis, $2.7 \%$ had neurologic manifestations, and $<1 \%$ had carditis [10]. Neither study identified secondary erythema migrans. In claims data, the incidence of facial palsy was highest in young men $10-14$ years, a newly identified high risk group [10]. We found that most Lyme disease cases were diagnosed in the summer, with the exception of Lyme arthritis, which was more evenly distributed throughout the fall and winter. The strong seasonal association with disseminated Lyme disease, especially the increased odds of Lyme arthritis in winter, is in line with prior surveillance findings that arthritis is the most common manifestation among Lyme disease cases with illness onset during December to March [11].

No prior quantitative epidemiologic studies have examined the relation between SES or health care factors and risk of Lyme disease manifestations. In this study, we observed associations with MA, primary care contact, and setting of diagnosis. Eligibility for MA is determined by federal and state poverty thresholds [40], and is used as an indicator of low SES in EHR studies [31]. Individuals who regularly see a primary care provider may be less likely to delay care. The higher risk of disseminated disease in inpatient settings likely reflects the acute severity of some manifestations, particularly Lyme carditis, which can be fatal, or neurologic symptoms like facial nerve palsy. In prior qualitative research with Geisinger Lyme disease patients, delayed diagnosis and treatment was attributed to appraisal delays (e.g., due to symptom misattribution, intermittent symptoms, atypical or no erythema migrans), behavioral delays in seeking care (e.g., due to inadequate health insurance) and misdiagnosis in urgent care or emergency settings [41]. The protective association observed here between urgent care and disseminated disease suggests that erythema migrans can often be reliably diagnosed in urgent care. We speculate that misdiagnosis in urgent or emergency settings would be more likely with atypical erythema migrans or in cases without any rash, which we could not reliably assess in this study.

This study had some limitations. We could not account for care provided outside of Geisinger, which could be a source of missing data, although the Geisinger health system provides primary, specialty, urgent, and emergency health care services. This could explain our observations of some Lyme disease diagnoses without antibiotic treatment or disseminated stage cases without a record of positive serology, although misclassification of Lyme disease stage is also a possibility. However, sensitivity analyses restricting to persons with antibiotic orders and disseminated diagnoses with positive serology did not affect our inferences. We were not able to classify $38 \%$ of Lyme disease cases by stage of disease. The differences in demographic and health care-related variables we observed between Lyme disease cases that could and could not be classified by stage may have influenced our results. However, the percentage of unclassified cases decreased 
over the study period, as more specific diagnoses were recorded and the richness of narrative free text increased over time. Free text notes were not available from the inpatient setting, which may have resulted in disseminated stage case misclassification, or from phone calls, which may have resulted in early stage case misclassification. While we accounted for common spelling errors, abbreviations, and excluded simple instances of negations or diagnoses not related to the patient in the free text algorithm, extracting accurate clinical information from free text encounter notes is notoriously challenging due to nonstandard grammar, common shorthand and misspelling, and auto-generated text strings [42]. Diagnostic coding accuracy likely varies by provider characteristics, and setting, with higher accuracy for inpatient diagnoses that are often updated at discharge [43]. Using EDG name diagnoses, in addition to ICD-9 and ICD-10 diagnosis codes, allowed for increased flexibility and specificity of Lyme disease manifestations. Although EDG name diagnoses may have limited generalizability to non-Epic EHR, Epic is one of the largest providers of EHR to hospitals in the US. Geisinger's primary care population is representative of the region's general population in terms of age and sex [44]; however, findings from a largely rural and suburban, majority non-Hispanic white population may not be transportable to other populations.

\section{Conclusions}

This is the first study to categorize Lyme disease cases by clinical stage and manifestation using both diagnoses and narrative text data from the EHR. Methods for identifying Lyme disease cases by stage and manifestation are critical for Lyme disease epidemiology, for both surveillance and inferential analyses. We found novel evidence that lower SES was associated with higher risk of disseminated Lyme disease, while primary care contact and diagnosis in the urgent care setting were consistently associated with lower risk of disseminated manifestations. Early Lyme disease causes relatively mild symptoms, and uncomplicated cases often respond well to short courses of oral antibiotics. In contrast, disseminated Lyme disease can be severe enough to require hospitalization, and in rare cases of Lyme carditis, can be difficult to treat or even fatal [45]. Delayed diagnosis, which makes disseminated infection more likely, is also a risk factors for post-treatment Lyme disease syndrome $[46,47]$. Public health interventions to prevent progression to disseminated stages of Lyme disease, especially in vulnerable groups, are necessary to reduce the substantial health care costs of Lyme disease [48].

\section{Supplementary Information}

The online version contains supplementary material available at https://doi. org/10.1186/s12879-021-06959-y.

Additional file 1: Table S1. Lyme disease diagnoses used to identify Lyme disease cases and to classify by clinical stage and manifestation. Table S2. Co-diagnoses used to identify Lyme disease cases and to classify by clinical stage and manifestation. Table S3. Selected characteristics of 4530 Lyme disease cases classified by stage, by source of staging information. Table S4. Selected characteristics of 7310 Lyme disease cases, classified ( $n=4530)$ vs. not classified $(n=2870)$ by stage. Table S5. Sensitivity analysis: adjusted associations (risk ratio, 95\% confidence interval) of independent variables with Lyme disease stage (disseminated vs. early stage), excluding disseminated Lyme disease cases without an lgG+ western blot OR ElA+/lgM+ western blot within \pm 30 days of Lyme disease diagnosis. Table S6. Sensitivity analysis: adjusted associations (risk ratio, 95\% confidence interval) of independent variables with Lyme disease stage (disseminated vs. early stage), excluding diagnoses without an appropriate antibiotic order within \pm 30 days of Lyme disease diagnosis.

\section{Acknowledgements}

The authors thank Dione G. Mercer for project management and Joseph J. DeWalle for cartography (Geisinger Department of Population Health Sciences).

\section{Authors' contributions}

$\mathrm{KM}, \mathrm{JP}$, and BS contributed to the conception and design of the study. BS and $\mathrm{AH}$ acquired the data. KM, JP, and BS analyzed and interpreted data. KM and BS drafted the initial manuscript; MP critically reviewed the manuscript. All authors revised the final manuscript. All authors read and approved the final manuscript.

\section{Funding}

This work was supported by the Steven \& Alexandra Cohen Foundation. The sponsors had no role in the study design, data collection, analysis and interpretation of data, writing of the manuscript, nor in the decision to submit the article for publication.

\section{Availability of data and materials}

Individual-level medical record data containing protected health information are available with Geisinger IRB approval and a data use agreement.

\section{Declarations}

\section{Ethics approval and consent to participate}

The Geisinger Institutional Review Board approved this study and waived informed consent. Data were collected for non-research purposes and consent was waived because it would be a burden on the patient if they would have to come into a visit to review and sign a consent, as some patients are not seen regularly. It would have been impractical for both the patient as well as study staff to contact thousands of patients to participate in the study.

\section{Consent for publication}

Not applicable.

\section{Competing interests}

The authors declare that they have no competing interests.

\author{
Author details \\ ${ }^{1}$ Department of Environmental Health and Engineering, Johns Hopkins \\ Bloomberg School of Public Health, 615 N Wolfe St., W7604, Baltimore, MD, \\ USA. ${ }^{2}$ Department of Population Health Sciences, Geisinger, Danville, PA, USA. \\ ${ }^{3}$ Department of Epidemiology, Johns Hopkins Bloomberg School of Public \\ Health, Baltimore, MD, USA. ${ }^{4}$ Department of Medicine, Johns Hopkins School \\ of Medicine, Baltimore, MD, USA.
}


Received: 27 September 2020 Accepted: 8 December 2021

Published online: 20 December 2021

\section{References}

1. Eisen RJ, Kugeler KJ, Eisen L, Beard CB, Paddock CD. Tick-borne zoonoses in the United States: persistent and emerging threats to human health. ILAR J. 2017:58(3):319-35.

2. Kugeler KJ, Schwartz AM, Delorey MJ, Mead PS, Hinckley AF. Estimating the frequency of lyme disease diagnoses, United States, 2010-2018. Emerg Infect Dis. 2021;27(2):616-9.

3. Steere AC, Strle F, Wormser GP, Hu LT, Branda JA, Hovius JW, et al. Lyme borreliosis. Nat Rev Dis Prim. 2016;2:16090.

4. Steere AC, Sikand VK. The presenting manifestations of lyme disease. N Engl J Med. 2003;348(24):2472-4.

5. Wormser GP, Dattwyler RJ, Shapiro ED, Halperin JJ, Steere AC, Klempner MS, et al. The clinical assessment, treatment, and prevention of lyme disease, human granulocytic anaplasmosis, and babesiosis: clinical practice guidelines by the Infectious Diseases Society of America. Clin Infect Dis. 2006;43(9):1089-134.

6. Sanchez E, Vannier E, Wormser GP, Hu LT. Diagnosis, treatment, and prevention of lyme disease, human granulocytic anaplasmosis, and babesiosis: a review. JAMA. 2016:315(16):1767-77.

7. Eisen L, Eisen RJ. Critical evaluation of the linkage between tick-based risk measures and the occurrence of lyme disease cases. J Med Entomol. 2016;53(5):1050-62

8. Tibbles CD, Edlow JA. Does this patient have erythema migrans? JAMA. 2007:297(23):2617-27

9. Aucott J, Morrison C, Munoz B, Rowe PC, Schwarzwalder A, West SK. Diagnostic challenges of early lyme disease: lessons from a community case series. BMC Infect Dis. 2009;9:79.

10. Kwit NA, Nelson CA, Max R, Mead PS. Risk factors for clinician-diagnosed lyme arthritis, facial palsy, carditis, and meningitis in patients from highincidence states. Open Forum Infect Dis. 2018:5(1): ofx254.

11. Schwartz AM, Hinckley AF, Mead PS, Hook SA, Kugeler KJ. Surveillance for lyme disease-United States, 2008-2015. MMWR Surveill Summ. 2017;66(22):1

12. Strle F, Wormser GP, Mead P, Dhaduvai K, Longo MV, Adenikinju O, et al. Gender disparity between cutaneous and non-cutaneous manifestations of lyme borreliosis. PLoS ONE. 2013;8(5): e64110.

13. Fix AD, Peña CA, Strickland GT. Racial differences in reported lyme disease incidence. Am J Epidemiol. 2000;152(8):756-9.

14. Costello JM, Alexander ME, Greco KM, Perez-Atayde AR, Laussen PC. Lyme carditis in children: presentation, predictive factors, and clinical course. Pediatrics. 2009:123(5):e835-41.

15. Johnson KO, Nelder MP, Russell C, Li Y, Badiani T, Sander B, et al. Clinical manifestations of reported lyme disease cases in Ontario, Canada: 2005-2014. PLoS ONE. 2018;13(6): e0198509.

16. Forrester JD, Meiman J, Mullins J, Nelson R, Ertel SH, Cartter M, et al. Notes from the field: update on lyme carditis, groups at high risk, and frequency of associated sudden cardiac death-United States. MMWR Morb Mortal Wkly Rep. 2014;63(43):982-3.

17. Weitzner E, Visintainer P, Wormser GP. Impact of patient age on clinical features, serologic test reactivity and long-term outcome of culture-confirmed early lyme disease. Diagn Microbiol Infect Dis. 2017;89(4):300-2.

18. Weitzner E, Visintainer P, Wormser GP. Comparison of males versus females with culture-confirmed early lyme disease at presentation and at 11-20 years after diagnosis. Diagn Microbiol Infect Dis. 2016;85(4):493-5.

19. Liao KP, Cai T, Savova GK, Murphy SN, Karlson EW, Ananthakrishnan AN, et al. Development of phenotype algorithms using electronic medical records and incorporating natural language processing. BMJ. 2015;350:h1885-h1885.

20. Moon KA, Pollak J, Hirsch AG, Aucott JN, Nordberg C, Heaney CD, et al. Epidemiology of lyme disease in Pennsylvania 2006-2014 using electronic health records. Ticks Tick Borne Dis. 2019;10(2):241-50.

21. Moon KA, Pollak J, Poulsen MN, Hirsch AG, DeWalle J, Heaney CD, et al. Peridomestic and community-wide landscape risk factors for Lyme disease across a range of community contexts in Pennsylvania. Environ Res. 2019;178(April): 108649
22. Tseng Y-J, Cami A, Goldmann DA, DeMaria A, Mandl KD. Using nationwide health insurance claims data to augment lyme disease surveillance. Vector-Borne Zoonotic Dis. 2015;15(10):591-6.

23. Lantos PM, Branda JA, Boggan JC, Chudgar SM, Wilson EA, Ruffin F, et al. Poor positive predictive value of lyme disease serologic testing in an area of low disease incidence. Clin Infect Dis. 2015;61(9):1374-80.

24. Nelson CA, Saha S, Kugeler KJ, Delorey MJ, Shankar MB, Hinckley AF, et al. Incidence of clinician-diagnosed lyme disease, United States, 2005-2010. Emerg Infect Dis. 2015:21(9):1625-31.

25. Eliassen KE, Berild D, Reiso H, Grude N, Christophersen KS, Finckenhagen $C$, et al. Incidence and antibiotic treatment of erythema migrans in Norway 2005-2009. Ticks Tick Borne Dis. 2017;8(1):1-8.

26. Botman E, Ang CW, Joosten JHK, Slottje P, Van Der Wouden JC, Maarsingh OR. Diagnostic behaviour of general practitioners when suspecting lyme disease: a database study from 2010-2015. BMC Fam Pract. 2018;19(1):1-9.

27. Moore SM, Eisen RJ, Monaghan A, Mead P. Meteorological influences on the seasonality of lyme disease in the United States. Am J Trop Med Hyg. 2014;90(3):486-96.

28. Levi T, Keesing F, Oggenfuss K, Ostfeld RS. Accelerated phenology of blacklegged ticks under climate warming. Philos Trans R Soc B Biol Sci. 2015;370(1665):1-8

29. Barbour AG, Fish D. The biological and social phenomenon of lyme disease. Science (80-). 1993:260(5114):1610-6.

30. Centers for Medicare \& Medicaid Services. Medicaid \& CHIP in Pennsylvania. 2020. https://www.medicaid.gov/state-overviews/stateprofile.html? state $=$ pennsylvania.

31. Casey JA, Pollak J, Glymour MM, Mayeda ER, Hirsch AG, Schwartz BS. Measures of SES for electronic health record-based research. Am J Prev Med. 2018;54(3):430-9.

32. Mead PS. Epidemiology of lyme disease. Infect Dis Clin North Am. 2015;29(2):187-210

33. Seriburi V, Ndukwe N, Chang Z, Cox ME, Wormser GP. High frequency of false positive lgM immunoblots for Borrelia burgdorferi in clinical practice. Clin Microbiol Infect. 2012;18(12):1236-40.

34. Centers for Disease Control and Prevention. Recommendations for test performance and interpretation from the second national conference on serologic diagnosis of lyme disease. MMWR. 1995:44(31):590-1.

35. U.S. Census Bureau. 2010 census urban and rural classification and urban area criteria. 2018. https://www.census.gov/programs-surveys/geogr aphy/guidance/geo-areas/urban-rural/2010-urban-rural.html. Accessed 11 Dec 2019.

36. Douthit N, Kiv S, Dwolatzky T, Biswas S. Exposing some important barriers to health care access in the rural USA. Public Health. 2015;129(6):611-20.

37. Zou G. A modified Poisson regression approach to prospective studies with binary data. Am J Epidemiol. 2004;159(7):702-6

38. Newton KM, Peissig PL, Kho AN, Bielinski SJ, Berg RL, Choudhary V, et al. Validation of electronic medical record-based phenotyping algorithms: results and lessons learned from the eMERGE network. J Am Med Inf Assoc. 2013;20(e1):e147-54.

39. Cartter ML, Lynfield R, Feldman KA, Hook SA, Hinckley AF. Lyme disease surveillance in the United States: looking for ways to cut the Gordian knot. Zoonoses Public Health. 2018:65(2):227-9.

40. Henry J. Kaiser Family Foundation. Medicaid and CHIP eligibility, enrollment, renewal, and cost-sharing policies as of January 2020: findings from a 50-state survey. 2020. https://www.kff.org/medicaid/report/medic aid-and-chip-eligibility-enrollment-and-cost-sharing-policies-as-of-janua ry-2020-findings-from-a-50-state-survey/.

41. Hirsch AG, Herman RJ, Rebman A, Moon KA, Aucott J, Heaney C, et al. Obstacles to diagnosis and treatment of lyme disease in the USA: a qualitative study. BMJ Open. 2018;8:1-7.

42. Meystre SM, Savova GK, Kipper-Schuler KC, Hurdle JF. Extracting information from textual documents in the electronic health record: a review of recent research. Yearb Med Inform. 2008;17:128-44.

43. Callahan A, Shah NH, Chen JH. Research and reporting considerations for observational studies using electronic health record data. Ann Intern Med. 2020;172(11):S79-84.

44. Casey JA, Savitz DA, Rasmussen SG, Ogburn EL, Pollak J, Mercer DG, et al. Unconventional natural gas development and birth outcomes in Pennsylvania. USA Epidemiol. 2016;27(2):163-72. 
45. Sanchez JL. Clinical manifestations and treatment of lyme disease. Clin Lab Med. 2015;35(4):765-78.

46. Aucott J. Posttreatment lyme disease syndrome. Infect Dis Clin North Am. 2015;29(2):309-23.

47. Hirsch AG, Poulsen MN, Nordberg C, Moon KA, Rebman AW, Aucott $\mathrm{JN}$, et al. Risk factors and outcomes of treatment delays in lyme disease: a population-based retrospective cohort study. Front Med. 2020;7(November):1-10.

48. Adrion ER, Aucott J, Lemke KW, Weiner JP. Health care costs, utilization and patterns of care following lyme disease. PLoS ONE. 2015;10(2): e0116767.

\section{Publisher's Note}

Springer Nature remains neutral with regard to jurisdictional claims in published maps and institutional affiliations.

- fast, convenient online submission

- thorough peer review by experienced researchers in your field

- rapid publication on acceptance

- support for research data, including large and complex data types

- gold Open Access which fosters wider collaboration and increased citations

- maximum visibility for your research: over $100 \mathrm{M}$ website views per year

At $\mathrm{BMC}$, research is always in progress.

Learn more biomedcentral.com/submissions 